G. Golański ${ }^{1}$, I. Pietryka², J. Jasak ${ }^{1}$, J. Słania ${ }^{3}$, P. Urbańczyk ${ }^{4}$, P. Wieczorek ${ }^{1}$

${ }^{1}$ Institue of Materials Engineering, Czestochowa University of Technology, Armii Krajowej 19, 42-200 Częstochowa, Poland,grisza@wip.pcz.pl

${ }^{2}$ Institue of Materials Engineering, Cracow University of Technology, Jana Pawła II 37, 31-864 Cracow, Poland

${ }^{3}$ Welding Departament, Czestochowa University of Technology, Armii Krajowej 19c, 42-200 Częstochowa, Poland

${ }^{4}$ UDT, W. Przybylaka 8, 41-300 Dąbrowa Górnicza, Poland

\title{
DEGRADATION OF MICROSTRUCTURE AND MECHANICAL PROPERTIES OF 15HM STEEL AFTER 420000 HOURS OF SERVICE
}

\begin{abstract}
The results of a microstructure examination and mechanical properties of 15HM (13CrMo4-5) steel are presented in the article. The examined elements are the samples taken from the live steam pipeline serviced for about 420000 hours at the temperature of about $510^{\circ} \mathrm{C}$, and pressure of $11 \mathrm{MPa}$. It has been shown that after long-term operation the examined steel has a ferritic-pearlitic microstructure with a dominant content of quasipolygonal ferrite. The processes of fragmentation of lamellar precipitates and their spheroidization were observed in pearlite. On the grain boundaries, single lamellar precipitations were observed. Moreover, numerous precipitations at the interface of three grain boundaries were revealed. The examined steel, despite its long-term service time, was characterized by the strength properties (YS, TS) slightly lower than the required minimum, the impact energy value KV equal to $20 \mathrm{~J}$, and the transition temperature shifted to a temperature above zero. Relatively low level of degradation of the microstructure and mechanical properties of the investigated steel can result from high stability of the ferritic-pearlitic microstructure.
\end{abstract}

Key words: low alloys steel, microstructure, mechanical properties

\section{INTRODUCTION}

Low-alloy 15HM (13CrMo4-5) steel is one of the basic creep resistance type of steel used for the decades in the installations in the electrical power industry and the petroleum chemistry industry to operate at the temperature up to $530-550^{\circ} \mathrm{C}$, depending on the calculated life agreed at the stage of planning. Such steel is used to make, e.g. cumulative chambers, steam heater coils, communication pipelines inside the boiler, pipelines of superheated steam in the collector or unit systems, and the pressure vessels.

The reliability of boilers and pipelines of steam power plants is a serious problem of a national power industry. Moreover, the national electrical power system is considerably exhausted, more than $90 \%$ of power units surpassed calculated operating time, which equals not only 100000 hours, but also 200-250 000 hours [1]. Therefore, a key issue is to undergo reliable diagnostic tests, whose aim is to assess a general state of the pressure elements of the 
power installations. The assessment of the current condition of steel used in the power industry, to specify its further safe service, requires the knowledge of changes and processes that have taken place in the microstructure and their influence on the steel properties. The results obtained on a specified stage of service allow describing the so called 'level of a material exhaustion' on the basis of an analysis of a microstructure, morphology of precipitations, and mechanical properties $[2,3,4]$. It is necessary to build and broaden the database and characteristics of both the materials used in the power industry and the joints welded after a long-term service under creeping conditions. The presented results of microstructure examinations and mechanical properties of 15HM (13CrMo4-5) steel after long-term service, as well as their analysis, are well matched to the above-mentioned issues.

\section{MATERIAL AND METHODOLOGY OF RESEARCH}

The material used for testing was 15HM (13CrMo4-5) steel, with its chemical composition presented in Table 1. The examined material was taken from the live steam pipeline of $\varphi 273$ x $28 \mathrm{~mm}$ size, exploited for about 420000 hours at the temperature of $510^{\circ} \mathrm{C}$, and the pressure of $11 \mathrm{MPa}$.

Table 1. Chemical composition of the examined steel, wt. \%

\begin{tabular}{|c|c|c|c|c|c|c|c|c|c|}
\hline $\mathrm{C}$ & $\mathrm{Si}$ & $\mathrm{Mn}$ & $\mathrm{P}$ & $\mathrm{S}$ & $\mathrm{Cr}$ & $\mathrm{Mo}$ & $\mathrm{Ni}$ & $\mathrm{Cu}$ & $\mathrm{Al}_{\text {met }}$ \\
\hline 0.19 & 0.31 & 0.55 & 0.009 & 0.012 & 0.64 & 0.40 & 0.12 & 0.09 & 0.015 \\
\hline
\end{tabular}

The chemical composition of the examined steel, in comparison to the requirements included in the standard specification [5] (including possible deviation of the composition), is characterized by a slightly lower than a minimal content of chromium (min. $0.70 \pm 0.03 \%$ ), and a maximum possible content of carbon.

The observation and registration of microstructure images were made by the optical microscope Axiovert $25(\mathrm{OM})$, and the electron scanning microscope Jeol JSM 6610LV (SEM) on traditionally prepared metallographic specimens etched with nital. The transmission electron microscope Philips $301 \mathrm{G}$ was used to identify precipitations using the extraction carbon replicas. Examinations of mechanical properties included: hardness measurement by the Vicker's method using hardness tester Future-Tech FV-700 with a load of an intender of $30 \mathrm{kG}(294 \mathrm{~N})$, a static tensile test made by testing machine MTS-810 on round test samples with their initial measuring diameter $d_{o}=8 \mathrm{~mm}$, and the Charpy impact energy test on the traditional specimens with a V-notch. Results of hardness measurement are the mean of five measurements, while the results of the impact energy test and static test of tension are the mean of three measurements. The tests of mechanical properties were performed on the longitudinal test samples at room temperature. Due to the fact that the properties of the examined element before the service were not known, the obtained results of mechanical properties were compared to the standard requirements [5]. In the case of the impact energy test, the value of $27 \mathrm{~J}$ was assumed as the criterion of minimum ductility. The nil ductility transition temperature was determined for the criterion $\mathrm{KV}=27 \mathrm{~J}$, by heating up the test samples in the temperature range of $+20 \div+100^{\circ} \mathrm{C}$, using water as an agent. 


\section{RESEARCH RESULTS AND THEIR DISCUSSION}

\section{Microstructure of 15HM (13CrMo4-5) steel after long-term service}

The performed microstructural study has shown that the tested steel after service had a ferritic-pearlitic microstructure (Fig. 1). In the microstructure, a dominating phase was quasipolygonal ferrite, with a volume fraction of about $70 \%$, characterized by numerous precipitations of different sizes inside grains. Considerably less, about $10 \%$ was polygonal ferrite, characterized by a small amount of precipitations inside grains. The volume fraction of pearlite was about $20 \%$. A level of pearlite degradation was slight - fragmentation and spheroidization of lamellar precipitations in pearlite was observed.
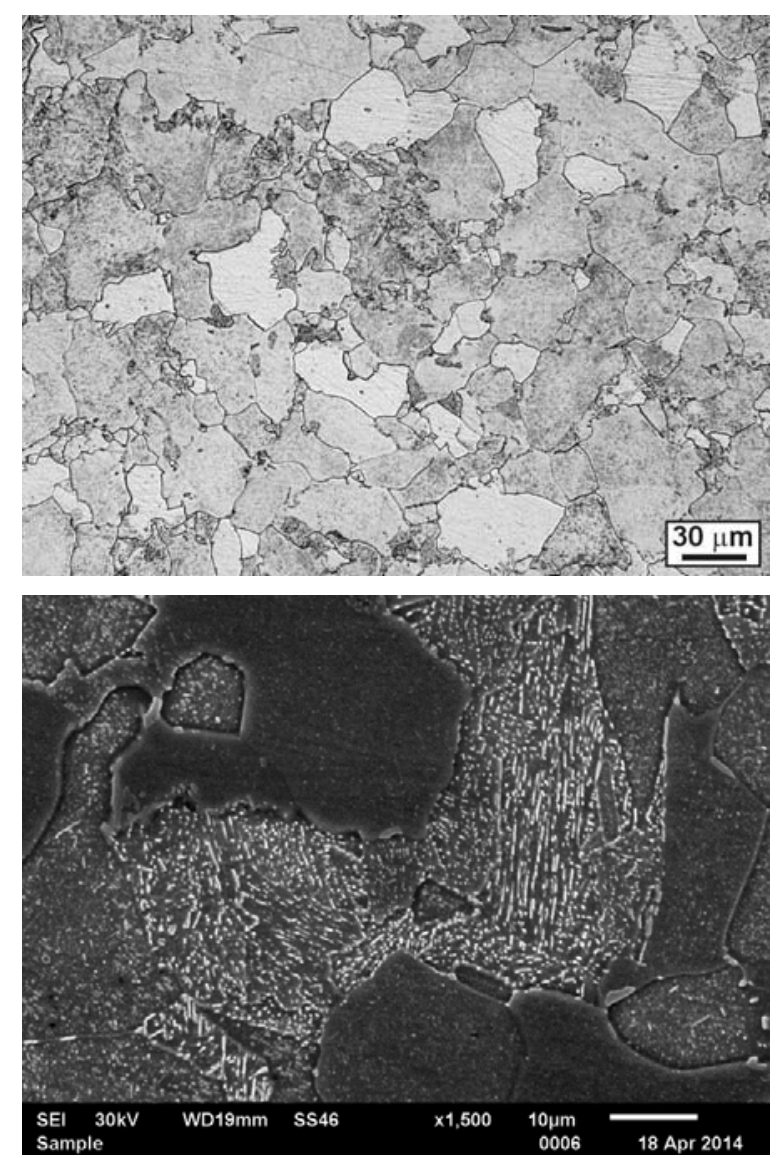

Fig. 1. Microstructure of $15 \mathrm{HM}$ steel after service

On ferrite grain boundaries, single large precipitations were revealed, with their shape similar to lamellar and/or lump shape. Moreover, carbide precipitations at the interface of three boundaries were observed. It is very unfavourable, as it enables generating creeping voids with the intercrystalline cracking mechanism in the mentioned areas (Fig. 2.) Size of the ferrite grain in the microstructure, specified by the drawing standards [6], was $7 / 8$ which refers to the average diameter of the grain amounting to $31.2 / 22.1 \mu \mathrm{m}$. While in the pearlite/ bainite areas it was $-8 / 9(22.1 / 15.6 \mu \mathrm{m})$. According to studies [7], in CrMo type of steel, characterized by the size of the prior austenite grain smaller than $10 \mu \mathrm{m}$, the probability of brittleness occurrence, connected with an unfavourable influence of phosphorus during the service, is insignificant. 

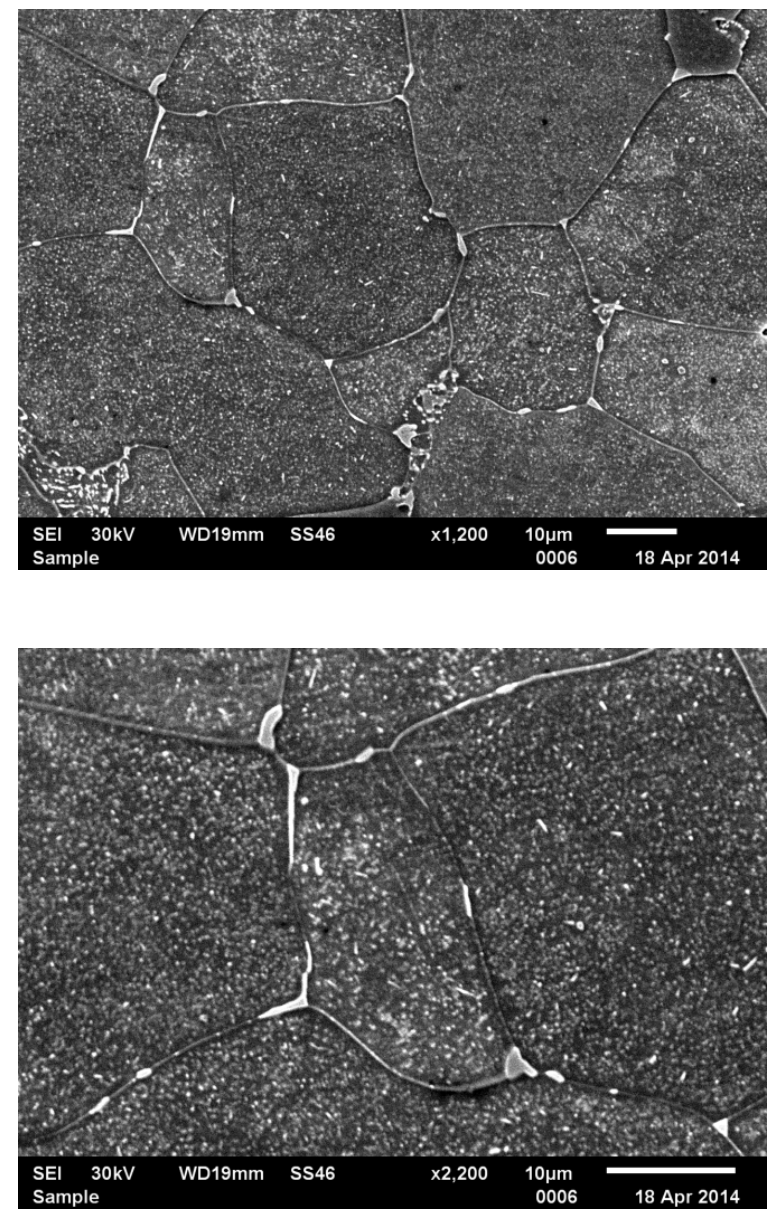

Fig. 2. Precipitations on the grain boundaries and at the interface of three boundaries in CrMo steel after service

In the microstructure of the examined steel, however, the near boundary areas depleted of precipitations, were not observed. These areas, according to numerous studies $[8,9,10]$, are one of the major mechanisms of degradation of low-alloyed microstructures of CrMo and CrMoV steels, long-term serviced under creeping conditions.

In the balanced condition in CrMo steels, the type of carbides depends on the proportion of molybdenum, chromium, and manganese to carbon. $\mathrm{M}_{3} \mathrm{C}, \mathrm{M}_{23} \mathrm{C}_{6}$ and $\mathrm{M}_{2} \mathrm{C}$ carbides were observed in the balanced condition of the mentioned steels $[11,12]$. Short tempering time during the heat treatment process, however, does not allow obtaining thermodynamic balance between the matrix and precipitated carbides. The process of precipitation takes place further during the service at the elevated temperature. Identification of precipitations in the examined steel in the condition after service showed the occurrence of $\mathrm{M}_{3} \mathrm{C}$ carbides in the areas of degraded pearlite, $\mathrm{M}_{23} \mathrm{C}_{6}, \mathrm{M}_{2} \mathrm{C}$ and $\mathrm{M}_{6} \mathrm{C}$ carbides inside ferrite grains, and $\mathrm{M}_{23} \mathrm{C}_{6}$ carbides on the ferrite grains. Despite what has been suggested for many years $[13,14]$, the presence of $\mathrm{M}_{6} \mathrm{C}$ carbide in the microstructure does not disqualify the usefulness of creep-resisting steels in further service. The occurrence of $\mathrm{M}_{6} \mathrm{C}$ precipitations in the microstructure leads into a considerable matrix depletion of molybdenum, and a disappearance of dispersive precipitations of the $\mathrm{M}_{6} \mathrm{C}$ type. As proved by the studies [13], it can lead into a reduction of creep resistance and a decrease in cracking resistance. According to [15], also the process of coagulation of $\mathrm{M}_{23} \mathrm{C}_{6}$ carbides takes place at the expense of disappearance of fine dispersive precipitations of the $\mathrm{M}_{2} \mathrm{C}$ type. 


\section{Mechanical properties of 15HM (13CrMo4-5) steel after service}

Changes that take place in the microstructure during long term service of steels for power industry cause a decrease of their mechanical properties. The results of research on mechanical properties of the analysed steel with the requirements are presented in Table 2.

Table 2. Properties of 15HM (13CrMo4-5) steel after service with the requirements according to [5]

\begin{tabular}{|c|c|c|c|c|}
\hline YS, MPa & TS, MPa & El., $\%$ & KV, J & HV30 \\
\hline 280 & 436 & 27 & 20 & 124 \\
\hline min. 295 & min. 440 & min. 22 & min. 27 & ---- \\
\hline
\end{tabular}

Examinations of mechanical properties carried out by performing a static tension test showed that the examined steel after long-term service was characterized by strength properties (YS, TS) slightly lower, by about $5 \%$, than the minimum standard requirements, with the value of elongation meeting these requirements. High content of carbon in the chemical composition of the examined steel (Table 1) resulted in a high rate of YS and TS in the as-received state. Therefore, despite a decrease in these parameters, their rate after service is similar to the minimum requirements. A decrease in the strength properties of the examined steel during the service should be connected with the transformation of carbides $\mathrm{M}_{2} \mathrm{C} \rightarrow \mathrm{M}_{6} \mathrm{C}$, an increase of $\mathrm{M}_{23} \mathrm{C}_{6}$ carbides, and the matrix depletion of substitution elements (chromium and molybdenum), which leads to the decrease in the precipitation and solution strengthening, respectively. The study presented in the article [13] showed a considerable influence of the chromium and molybdenum distribution in the matrix and in the precipitations on inter alia the creep resistance, or resistance to cracking. Matrix depletion of the above elements in CrMo types of steel during the service leads to a decrease in the above properties. Hardness of examined steel amounted to $124 \mathrm{HV} 30$. The long-term service contributed to an increase in brittleness of CrMo steel. The value of impact energy KV of the examined steel after service was $20 \mathrm{~J}$. Low ductility of the investigated steel is also connected with the ductile to brittle transition temperature, shifted to a temperature above zero, which amounted to $+46^{\circ} \mathrm{C}$ for $\mathrm{KV}_{27 \mathrm{~J}}$ criterion. The impact energy value $\mathrm{KV}$ of the examined steel after a long-term service was on a satisfactory level, which results from high purity of the steel - low phosphorus content, as well as high content of carbon. Low content of phosphorus - one of the most dangerous additive in steels for power industry $[16,17]$ has an influence on the reduction of its role as a factor mostly responsible for the growth of brittleness of low-alloyed steels during the service. An increase in phosphorus concentration in the near boundary areas contributes to a decrease in their cohesion, which in consequence leads into a decrease in ductility and a shift of the transition temperature to a temperature above zero. The concentration of phosphorus on the grain boundary is the higher the lower the service temperature, and the higher the phosphorus content in the serviced steel/cast steel $[16,17]$. However, carbon atoms increase the cohesion of grain boundaries on the one hand, and prevent the phosphorus atoms from locating in the near boundary areas on the other hand [19]. 


\section{CONCLUSIONS}

Microstructure and mechanical properties of 15HM (13CrMo4-5) low-alloyed steel collected from the pipeline serviced for about 420000 hours at the temperature of $510^{\circ} \mathrm{C}$ were examined. Despite a very long service time declared, the research showed a relatively slight level of the microstructure degradation, including: fragmentation and spheroidization of carbides in pearlite, precipitation of carbides at the interface of three boundaries, and the occurrence of the $\mathrm{M}_{6} \mathrm{C}$ type carbides. The insignificant level of degradation probably results from the stable ferritic-pearlitic microstructure, favourable for this type of steel. This microstructure, despite the prior lower strengthening, guarantees slower processes of changes running in the microstructure. The slight level of microstructure degradation, in spite of a very long service time (over 50 years), is also reflected in surprisingly good mechanical properties of the analyzed steel. The strength properties (YS, TS) are insignificantly lower than the required minimum, and the resistance to cracking expressed with the impact energy value is also on the satisfactory level (even though the value is lower than required).

\section{REFERENCES}

1. Jasiński A.: Extented operational time of domestic power units - chances and threats [in Polish], Energetyka, 3 (2013), 551-556.

2. Dobrzański J.: Materials science interpretation of the life of steels for power plants [in Polish], Open Access Library, 3, 2011.

3. Dziuba - Kałuża M., Dobrzański J., Zieliński A.: Mechanical properties of Cr-Mo and Cr-Mo-V low-alloy steel welded joints after long-term service under creep conditions, Arch. Mater. Sc. Eng., 63 (2013), 5-12.

4. Dobrzański J., Krztoń H., Zieliński A.: Development of the precipitation processes in low-alloy Cr-Mo type steel for evolution of the material state after exceeding the assessed lifetime, J. Achiev. Mater. Manufac. Eng., 2, 23, (2007), 19-22.

5. PN-75/H-84024 Steels for elevated temperatures service. Grades.

6. PN-EN ISO 643:2012 Steels - Micrographic determination of the apparent grain size.

7. Khan S. A., Islam M. A.: Influence of prior austenite grain size on the degree of temper embrittlement in Cr-Mo steel, J. Mater. Eng. Perform., 16, (2007), 80-85.

8. Nguyen T. D., Sawada K., Kushima H., Tabuchi M., Kimura K.: Change of precipitation free zone during long - term creep in 2.25Cr-1Mo steel, Mater. Sc. Eng. A, 591A (2014), 130-135.

9. Golański G., Pietryka I., Słania J., Jasak J., Urbańczyk P., Microstructure and mechanical properties of welded joint of 12HMF steel after long - term service [in Polish], Welding Technology Review [Przegląd Spawalnictwa], 5, 2014, 49-53.

10. Joarder A., Sarma D. S., Cheruvu N. S.: Effect of long - term service exposure on microstructure and mechanical properties of a $\mathrm{CrMoV}$ steam turbine rotor steel, Metall. Trans., 22A (1991), 1811-1820.

11. Pigrova P. G.: Carbide diagrams and precipitation of alloying elements during aging of low-alloy steels, Metall. Mater. Trans. A, 27 (1996), 498-502.

12. Janovec J., Svoboda M., Vyrostkova A., Kroupa A.: Time-temperature-precipitation diagrams of carbide evolution in low alloy steels, Mater. Sc. Eng., 402A (2005), 288-293. 
13. Stevens R. A., Flewitt P. E. J.: The effect of phosphorus on the microstructure and creep properties of 2\%1/4\%Cr1\%Mo steel, Acta Metall., 5 (1986), 849-866.

14. Dobrzański J., Hernas A.: Correlation between phase composition and life-time of $1 \mathrm{Cr}-0.5 \mathrm{Mo}$ steels during long-term service at elevated temperatures, J. Mater. Proces. Technol., 53 (1995), 101-108.

15. Afrouz A., Collins M. J., Pilikngton R.: Microstructural examination of 1 Cr-0.5Mo steel during creep Met. Technol., 12 (1983), 461-463.

16. Stachura S., Stradomski Z., Golański G.: Phosphorus in ferroalloys [in Polish], Hutnik Wiadomości Hutnicze, 5 (2001), 184-193.

17. Janovec J.: Nature of alloy steel intergranular embrittlement, Veda Publ., Bratislava, 1999.

18. Islam M. A., Novovic M., Bowen P., Knott J.F.: Effect of phosphorus segregation on fracture properties of 2.25Cr-1 Mo pressure vessel steel, J. Mater. Eng. Perform., 12, 3 (2003), 244-248.

19. Suzuki S., Obata M., Abiko K., Kimura H.: Effect of carbon on the grain boundary segregation of phosphorus in $\alpha$ - iron, Sc. Metall. 17 (1983), 1325-1328. 